FLOORS 


\section{ESSENCE BOOKS ON BUILDING}

General Editor: J. H. Cheetham, ARIBA

Other titles in the Essence Books on Building Series

FISHER: Walls

LAUNDER: Foundations

OWEN: Roofs

ROSENTHAL: Structure

SMITH: Brickwork 


\section{FLOORS}

Gordon Hale Dipl. Arch; ARIBA

Senior Lecturer,

Shirecliffe College of Further Education,

Sheffield 


\section{(C)1972 Gordon Hale}

All rights reserved. No part of this publication may be reproduced or transmitted, in any form or by any means, without permission.

SBN 333135563

ISBN 978-0-333-13556-3 ISBN 978-1-349-01502-3 (eBook)

DOI 10.1007/978-1-349-01502-3

Published by

\section{THE MACMILLAN PRESS LIMITED}

London and Basingstoke Associated companies in New York, Melbourne, Toronto, Johannesburg, Dublin and Madras. 


\section{Preface}

This book is intended primarily as a textbook for architectural, building and surveying students. As such, it should be of particular help to those studying for National Diplomas, National Certificates and the General Certificate of Education at both Ordinary and Advanced Levels in building construction.

It has been my intention to show currently-used methods of floor construction and perhaps more important, to explain why these methods have been adopted.

We live in a period of transition and rapid development. Change is so rapid that the constructional processes of today may well become obsolescent tomorrow. In producing this book, therefore, I have not tried to forecast future trends. Equally, I have not discarded consideration of some processes which might be thought a little dated but have simply attempted to describe and illustrate methods of designing and constructing floors that are in general use today.

Most types of floor construction have derived from the need to solve certain specific problems. Some of the solutions to these problems have been evolved by a process of trial and error; others by an understanding of the properties of new materials so that they may be used in floors to their best advantage. Many of the fundamental problems and the classical solutions to them are dealt with in the historical introduction. Subsequent chapters describe the functions of the floor and show how it must be designed and constructed to safely fulfil them.

Much has already been published on floors as such, but in sifting through existing information, I have tried to select that which seems particularly relevant to the essence of the subject. In doing so, I freely acknowledge my indebtedness to many other writers, to journals which in recent years have published specialist articles on floor construction and not least, to the Building Research Station, whose excellent Digests are so invaluable.

Where due acknowledgement has not been made in the text, I can only offer my apologies for inadvertent omissions and explain that after many years' practical experience as an architect, together with lecturing upon the subject, it has not always been possible to track down every original source of information.

G.H. 


\section{Acknowledgements}

Protim Ltd. $\quad$ preservation of timber

Archibald Low \& Sons Ltd. "Elaflor" elevated floor

Filigree Ltd.

pre-cast floor units

The Expanded Metal Co. Ltd. Details of Hy-rib

Brooklyns Westbrick Ltd. pre-cast floor units

Finlock Group Ltd. pre-cast floor units and composite floor construction

Horace W. Cullum \& Co. Ltd. sprung and sound proof floors

Gradus Ltd.

Sankey-Sheldon Ltd.

Concrete Ltd.

Building Research Station

Airscrew-Weyroc Ltd. sprung and sound proof floors Unistrut elevated floor "Bison" pre-cast and pre-stressed floor units

Digests on floor finishes, industrial type floors, suspended timber floors and information from "Principles of Modern Building"

details of chipboard coverings 


\section{Contents}

Introduction . . . . . . . . . . . . . . . . $x i$

1. FUNCTIONS OF THE FLOOR
(a) Strength and stability . . . . . . . . . . . . . 1
(b) Deflection . . . . . . . . . . . . . . . 2
(c) Fire protection . . . . . . . . . . . . . 3
(d) Thermal and sound insulation . . . . . . . . . . 4
(e) Resistance to moisture . . . . . . . . . . . . . . 6
(f) Durability . . . . . . . . . . . . . . . 7

3. SUSPENDED TIMBER GROUND FLOORS
(a) Comparison with solid ground floors . . . . . . 16
(b) Softwood boarded floors . . . . . . . . . . 16
(c) Shrinkage . . . . . . . . . . . . . . . 21
(d) Chipboard floors . . . . . . . . . . . . . . 21
(e) Hardwood strip floors . . . . . . . . . . . . 22
(f) Underfloor ventilation . . . . . . . . . . . 25
(g) Protection from dampness . . . . . . . . . 26
(h) Trimming of fireplace hearths . . . . . . . . . 26

4. SUSPENDED TIMBER UPPER FLOORS
(a) Limitations
(b) Basic construction . . . . . . . . . . . . . . . 28
(c) End support of floor joists . . . . . . . . . . . . . 31
(d) Industrialized methods of construction _ . . . . . . 33
(e) Double floors . . . . . . . . . . . . . . . . 33

5. PRESERVATION OF TIMBER FLOORS
(a) Fungus attack
(b) Dry rot . . .
(c) Cellar fungus . . . . . . . . . . . . . . . . . 38
(d) Pore fungus . . . . . . . . . . . . . . . . . . 38 
(e) Beetle attack . . . . . . . . . . . . . . . . . 40

(i) Furniture beetle . . . . . . . . . . . . 41

(ii) Death watch beetle . . . . . . . . . . 41

(iii) House Longhorn beetle . . . . . . . . . 41

(iv) Wood-boring beetle . . . . . . . . . . . . . 42

(f) Preventative measures (. . . . . . . . . . . . . . . 42

\section{SOLID GROUND FLOORS}

(a) Hardcore filling . . . . . . . . . . . . . . . . . . . 44

(b) Blinding of hardcore . . . . . . . . . . . . . . . 46

(c) Damp-proof courses and barriers . . . . . . . . 46

(d) Cracking . . . . . . . . . . . . . . . . . . . . . . . . 46

(e) Floor finishes . . . . . . . . . . . . . . . . . . . . 47

(i) Cement screeds . . . . . . . . . . . . . . . . 48

(ii) Quarry tiles . . . . . . . . . . . . 49

(iii) Terrazzo: in situ and tiles . . . . . . . . 50

(iv) Cork tiles, Wood blocks . . . . . . . . . . 51

(v) Hardwood strip . . . . . . . . . . . . . . . 52

(vi) P.V.C. Tiles and P.V.C. sheet; Rubber sheet . . 54

(vii) Granolithic . . . . . . . . . . . . 54

(viii) Composition . . . . . . . . . . . . . . 55

(ix) Asphalt . . . . . . . . . . . . . . 55

(x) Pitch mastic . . . . . . . . . . . . . 55

\section{CONCRETE FLOORS CAST IN SITU}

(a) In situ slabs and pre-cast units compared . . . . . 57

(b) Types of in situ reinforced concrete floors . . . . 58

(c) Flush slabs . . . . . . . . . . . . . . . . . . . . . 58

(d) Beam-and-slab floors . . . . . . . . . . . . . 58

(e) Drop slab floors . . . . . . . . . . . . . . . . . 59

(f) "Waffle grid" slabs . . . . . . . . . . . . . . . 60

(g) Lift slab construction . . . . . . . . . . . . 61

(h) Simple flush slabs and beam-and-slab construction $\quad 63$

(i) Formwork for reinforced concrete floors . . . . . 63

(j) Placing of reinforcement . . . . . . . . . . . . . 63

(k) Placing of concrete. . . . . . . . . . . . . . 67

(l) Proprietary in situ floor systems c . . . . . . . 68

(m) Filler joist floors . . . . . . . . . . . . . . . . 70

(n) "Hollow pot" reinforced concrete floors . . . . . 70

8. PRECAST CONCRETE FLOORS

(a) Pre-cast beam and filler block floors . . . . . . 84

(b) Openings in concrete floors . . . . . . . . . 85

(c) Cellular and sheet steel floors $\quad$. . . . . . . . . . . 88

(d) Wood-wool filler floors . . . . . . . . . . . . 89 
9. SPECIALIZED FLOORS
(a) Spring floors
(b) Sound-proof and semi-sprung floors
(c) Cavity or elevated floors
(d) Open metal floors
(e) Corrosion-resistant floors . . . . . . . . . . . 98
(f) Floor ducts . . . . . . . . . . . . . . . 100

Bibliography . . . . . . . . . . . . . . 101

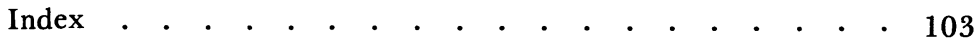




\section{Introduction}

The very earliest dwellings constructed or used by man were huts or caves. The floor was simply the area of ground enclosed by the walls. Man soon discovered, however, that by heaping up the earth so as to raise its level above the surrounding ground, the resultant floor was drier and consequently warmer, and generally improved the comfort of his home.

By pounding the raised earth with a pole or stamping on it with his feet, he found that he could consolidate the earth and thus produce a firm and reasonably durable surface.

Such floors are found today in the huts of primitive races and until a few years ago could also be found in some of the old rural cottages in this country.

They have many disadvantages however. In a very dry climate the surface tends to break up and is very dusty. In a wet climate the floor often becomes damp. At no time does it form a barrier to vegetable, insect or rodent life.

An improvement on the earth floor was to cover its surface with flat pieces of stone called flags. This type of floor is found in many of the medieval buildings still in existence in this country, although its use is far older than medieval times.

Such floors present a hard, extremely durable surface which can be kept reasonably clean and free from dust. Their greatest disadvantage is that they do not prevent the passage of damp. They are therefore invariably cold, and damp to the feet.

Because of these disadvantages, attempts were made from early times to construct ground floors of timber. Although this material was warmer to the touch, it was soon found that it decayed fairly rapidly if it was allowed to become damp from contact with earth. This in turn led to the timbers being raised up above the surface of the ground by supporting the floor on small walls. Although this was a more durable method of construction, it failed to solve the problem completely since damp rose in the walls and so eventually attacked the timber. Furthermore, there was no means of preventing vegetable growths from occurring below the floor. This, of course, further helped to make the wood damp, thus causing decay.

During the 17 th and 18 th centuries, much use was made of these suspended timber ground floors but by this time, the design of many 
buildings, particularly houses, was such that the ground was raised several feet above normal ground level, over a semi-basement. This ensured that the timbers of the floor were to a very great extent protected against damp. Consequently, these floors performed quite satisfactorily. The floor of the basement was usually surfaced with stone flags and was thus both damp and cold. But since such basements were used only as kitchens, laundries or stores, nobody minded very much, except possibly the servants who had to work in them!

In many districts stone, particularly in the form of large thin slabs suitable for flags, was very expensive. Various substitutes such as bricks and clay tiles were tried out. These suffered from being damp and cold in the same way as stone. Additionally, however, they often wore badly and had innumerable joints which were difficult to seal. Consequently they were often difficult to clean. Nevertheless, the appearance of such old warm red brick floors is of ten very pleasing.

During the 19th century the industrial revolution created the problem of housing many thousands of industrial workers cheaply, in new cottages built near to factories. Rents were low and consequently, landlords kept capital outlay to a minimum. This in turn resulted in extremely low standards of building. In their search for a cheap method of ground floor construction, builders frequently laid floor timbers direct on the ground where, of course, they were exposed to damp and rapidly deteriorated.

The fearful environmental conditions and poor building standards of the early 19 th century were a hazard to health and in Britain led directly to the Public Health legislation of 1848 and 1875. This resulted in local authorities being called upon to draw up building regulations and eventually to enforce regulation by inspection.

The new regulations affected the design of buildings in many ways. For instance, from now on the area of ground enclosed by the external walls of the buildings had to be covered by a layer of concrete and the space between the concrete and the floor above had to be adequately ventilated and the floor timbers protected from rising damp. This layer of concrete was important in helping to keep out damp and preventing vegetable growths. Of the greatest importance, however, was the conception of ventilating the air space. By this means, any damp air was dispelled and consequently, the risk of dry rot attack or insect attack on the timbers considerably lessened.

Insistence on the provision of a layer of concrete logically led to its being regarded as the ground floor itself. This was reasonably satisfactory, provided that it was faced with a suitable covering.

For many years the choice of covering was limited to clay tiles known as "quarries". These were very hard and durable, but also very cold. Quarry tile floors were often damp. Current legislation 
now makes it obligatory to provide a damp proof barrier within the concrete floor itself. In recent years, there has been a tremendous development of floor finishings available. Solid ground floors can now be designed so as to be both warm and dry to the feet, and durable and pleasant to look at.

From early times, the first and subsequent floors were of timber. Usually, they consisted of wide, thick planks laid on beams, or on joists spaced very close together. The beams were often square in section, since this was supposed to provide most strength and in any case, made it easier to support the beam and give an increased bearing area for the plank. Later, as good building timber became more scarce, a narrow but deeper section was adopted, since it was quickly realized that this provided the necessary strength while being more economical in the use of material.

Naturally, the span of such floors was limited. At the same time, it was generally found adequate to meet the needs of the times. In fact, it was not until the late 18 th and early 19 th centuries, when the first large industrial buildings were being erected, that the limitations of the timber floor became apparent.

Such floors were not capable of supporting the heavy loads of machinery, raw materials and finished products, nor did they offer much resistance to fire. In fact, by the middle of the 19 th century a series of disastrous warehouse fires led to a new type of floor being evolved for use in the new factories and warehouses that were springing up all over the North of England. This consisted of stone flags laid in lime mortar and supported on a flat brick vault. This, in turn, was supported by cast iron beams resting on cast iron columns (Fig. 1).

This type of floor provided a far greater degree of fire resistance and was adequate for most purposes although it was realized that there were severe strength limitations, cast iron possessing comparatively poor tensional strength.

Towards the end of the century a new material, mild steel, became available. This had far greater tensile strength than cast iron and was therefore capable of carrying equivalent loads over a far greater span. To produce a fire resistant floor of great strength, it was now possible to arrange a "grid" of principal and secondary beams supported on steel columns. In turn, the secondary beams supported filler joists of small section, spaced close together and supporting an in-filling of concrete (Fig. 2).

The resultant floor was capable of carrying very heavy loads and could also resist the affects of fire for several hours, depending on the thickness of concrete covering the steel. Floors of this type are still used today where very heavy loads have to be supported. In other situations, it is more usual to use a concrete floor reinforced with comparatively small diameter steel rods. This is far more 


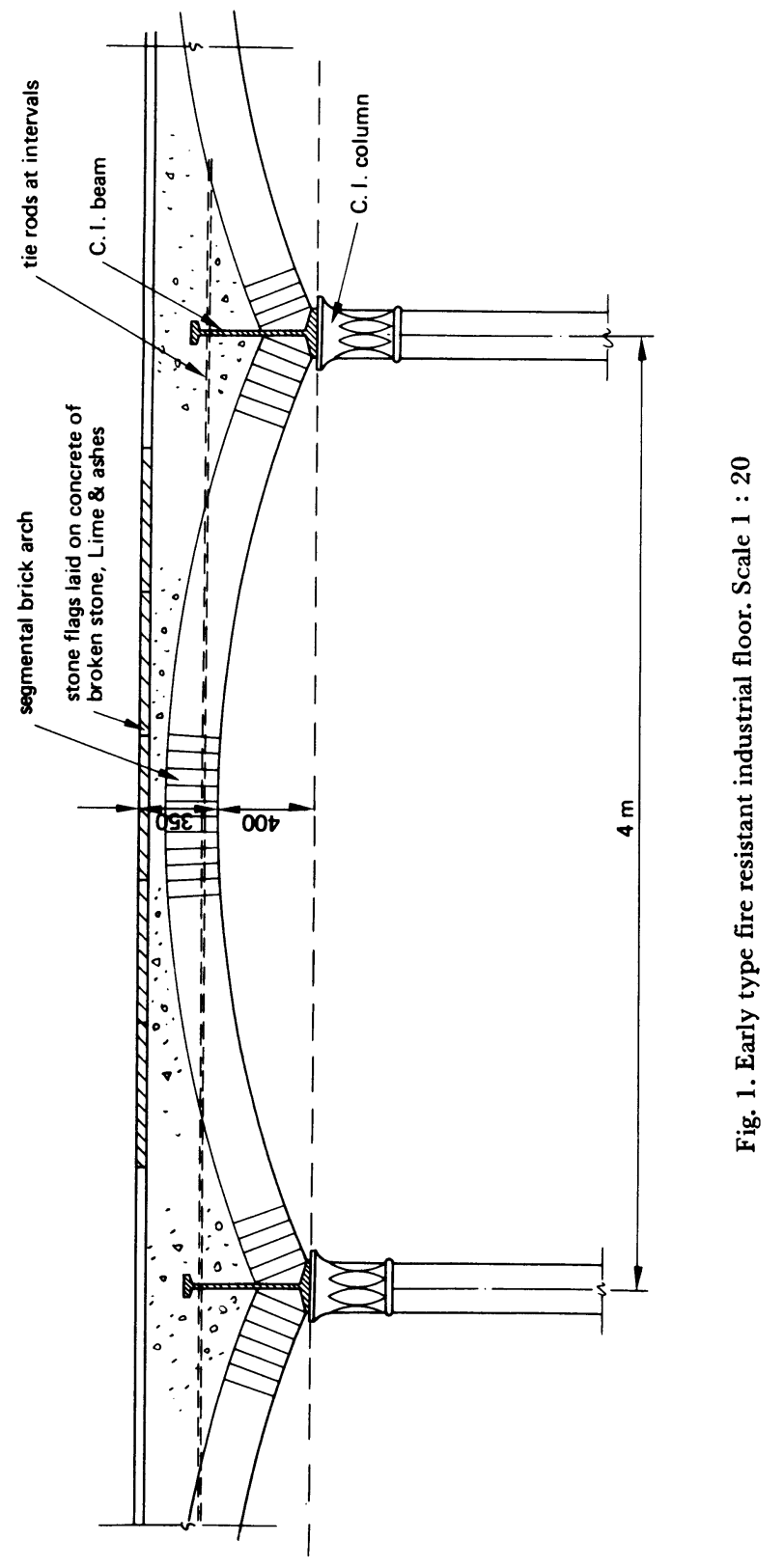


economical in its use of steel than the filler joist floor and consequently is much cheaper.

Timber floors are widely used today but their use is chiefly confined to small buildings where the loads to be supported are comparatively light and where the risk to the occupants in the event of fire, is not great.

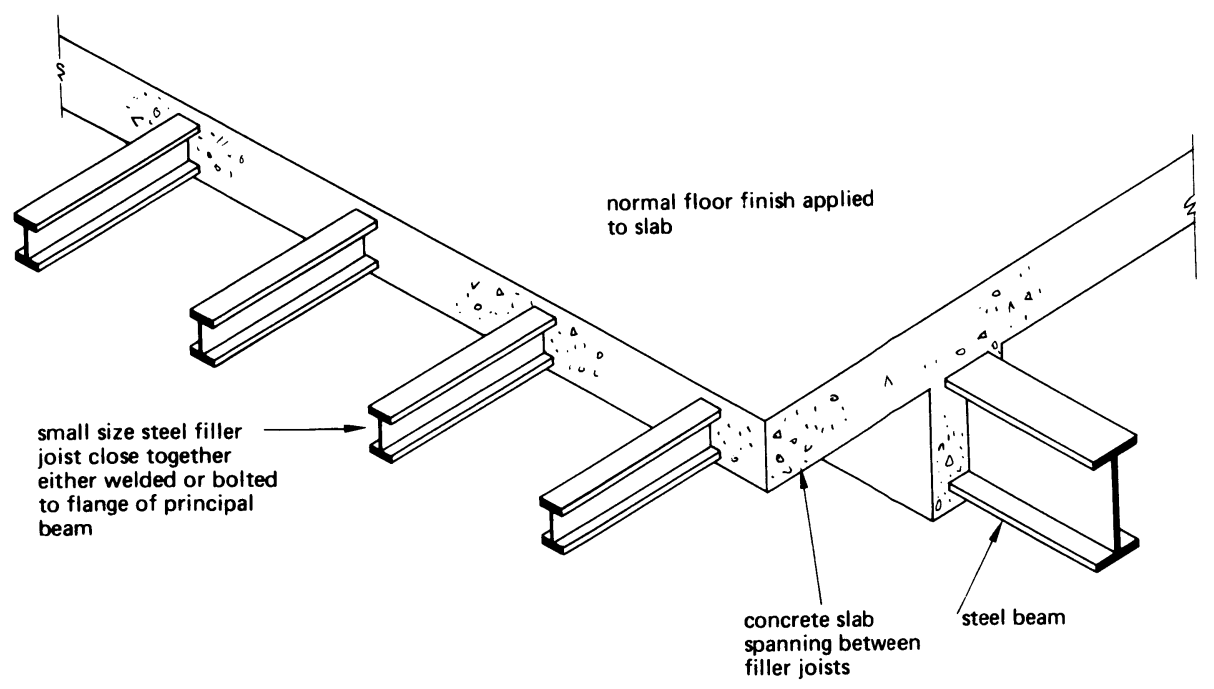

Fig. 2. Fire resistant filler joist floor 